\title{
The Role of Synaptic GTPase-Activating Protein in Neuronal Development and Synaptic Plasticity
}

\author{
Jee Hae Kim, Hey-Kyoung Lee, Kogo Takamiya, and Richard L. Huganir \\ Department of Neuroscience, Howard Hughes Medical Institute, Johns Hopkins University, School of Medicine, Baltimore, Maryland 21205
}

\begin{abstract}
Synaptic GTPase-activating protein (SynGAP) is a neuronal RasGAP (Ras GTPase-activating protein) that is selectively expressed in brain and highly enriched at excitatory synapses, where it negatively regulates Ras activity and its downstream signaling pathways. To investigate the physiological role of SynGAP in the brain, we have generated mutant mice lacking the SynGAP protein. These mice exhibit postnatal lethality, indicating that SynGAP plays a critical role during neuronal development. In addition, cell biological experiments show that neuronal cultures from mutant mice have more synaptic AMPA receptor clusters, suggesting that SynGAP regulates glutamate receptor synaptic targeting. Moreover, electrophysiological studies demonstrated that heterozygous mutant mice have a specific defect in hippocampal long-term potentiation (LTP). These studies show that the regulation of synaptic Ras signaling by SynGAP is important for proper neuronal development and glutamate receptor trafficking and is critical for the induction of LTP.
\end{abstract}

Key words: excitatory synapses; glutamate; long-term potentiation; long-term depression; postsynaptic density; AMPA receptors; NMDA receptors; Ras signaling

\section{Introduction}

Glutamatergic synapses mediate the majority of excitatory synaptic transmission in the mammalian CNS (Hollmann and Heinemann, 1994). The study of the physiology and structure of these synapses has yielded insights into many brain processes, including neuronal development, learning and memory, excitotoxicity, and neuropsychiatric diseases (Hollmann and Heinemann, 1994). At the excitatory synapse, the presynaptic neurotransmitter release machinery and endocytic compartments are concentrated at the nerve terminal, whereas the postsynaptic receptors and signaling molecules are tightly organized at and beneath the postsynaptic membrane (Garner et al., 2000; Scannevin and Huganir, 2000). Recently, the molecular dissection of synapses has identified many proteins that are involved in the sorting and targeting of synaptic proteins, including neurotransmitter receptors and ion channels (Scannevin and Huganir, 2000).

There are two classes of glutamate receptors: ligand-gated ionotropic glutamate receptors and G-protein-coupled metabotropic glutamate receptors (Hollmann and Heinemann, 1994); the organization and regulation of these receptors by associated molecules and other components of the postsynaptic membrane are beginning to be understood at a molecular level. Of the ligand-gated glutamate receptors, NMDA receptors have been implicated in many cellular processes contributing to neuronal development and differentiation, modulation of synaptic strength, and excitotoxicity. NMDA receptors are a central com-

Received 0ct. 21, 2002; revised Nov. 22, 2002; accepted Nov. 29, 2002.

Correspondence should be addressed to Dr. Richard L. Huganir, Howard Hughes Medical Institute/Johns Hopkins University, 904A Preclinical Teaching Building, 725 North Wolfe Street, Baltimore, MD 21205. E-mail: rhuganir@jhmi.edu.

J. Kim's present address: The Rockefeller University, Developmental Biology, 1230 York Avenue, New York, NY 10021.

Copyright $\odot 2003$ Society for Neuroscience $\quad$ 0270-6474/03/231119-06\$15.00/0 ponent of a large macromolecular complex with the members of the postsynaptic density-95 (PSD-95)/synapse-associated protein-90 (SAP90) protein family, recruiting a variety of proteins in close apposition (Scannevin and Huganir, 2000). One of these molecules is synaptic GTPase-activating protein (SynGAP), a novel neuronal Ras GTPase activating protein enriched at excitatory synapses (Chen et al., 1998; Kim et al., 1998) that may couple NMDA receptor function to synaptic Ras modulation.

Ras proteins are small G-proteins involved in the regulation of many important signal transduction processes that affect cellular growth and differentiation (Bokoch and Der, 1993; Marshall, 1996). In neurons, Ras signaling is essential for activation of the mitogen-activated protein kinase (MAPK) cascade by growth factors such as neurotrophins or by intracellular $\mathrm{Ca}^{2+}$ (Finkbeiner and Greenberg, 1996; Fukunaga and Miyamoto, 1998). The importance of the MAPK cascade in synaptic plasticity has been shown in several different systems, including Drosophila and Aplysia, as well in mammalian nervous systems (Brambilla et al., 1997; Kornhauser and Greenberg, 1997; Impey et al., 1999). The MAPK cascade has been shown to be involved in the induction and maintenance of long-term potentiation (LTP) (Brambilla et al., 1997; Sweatt, 2001), a common model of synaptic plasticity (Bliss and Collingridge, 1993; Nicoll and Malenka, 1995). The unique molecular and cellular features of SynGAP suggest that it may modulate Ras signaling at excitatory synapses and play an important role in synaptic plasticity.

In an effort to elucidate the physiological role of SynGAP, we used gene-targeting techniques to delete the SynGAP gene in mice. The SynGAP mutant mice die within the first week, indicating an essential role for SynGAP during early postnatal development. In neuronal cultures from mutant mice, the number of synaptic AMPA receptor clusters was increased, suggesting that SynGAP is important in the regulation of receptor synaptic tar- 
geting. Furthermore, electrophysiological studies in heterozygous mice show that LTP is decreased compared with that of the wild-type mice. Thus, these results show that SynGAP plays a critical role during neuronal development and may contribute to the complex regulation of signal transmission at synapses by affecting the organization and function of glutamate receptors.

\section{Materials and Methods}

Generation of the SynGAP knock-out mice. A bacterial artificial chromosome (BAC) genomic clone from the mouse strain 129 was obtained (Genome Systems, St. Louis, MO) using a primer set (AAGAAGGACAAGGCAGGCTAC and ATACTCCTTTATGGCTTTATG) designed to amplify a specific fragment between the $\mathrm{C} 2$ and GAP domains. The BAC clone 18793 was obtained and was analyzed by restriction mapping. A fragment of $\sim 13 \mathrm{~kb}$ digested with BamHI and HindIII restriction enzymes was chosen for additional analyses and to be used to make a targeted disruption in the SynGAP gene. After subcloning the BamHIHindIII fragment into pBluescript, the targeting vector was constructed by replacing the region containing two exons plus intronic sequences, after digestion with SacII and EcoRI, with the neo ${ }^{\mathrm{R}}$ cassette in the opposite orientation. Then the thymidine kinase gene was placed at the Bam HI and XhoI sites to aid during embryonic stem (ES) cell screening for homologous recombination events. The construct was linearized with HindIII and electroporated into 129 ES cells (Dr. A. Nagy, Mount Sinai Hospital, Toronto, Canada). Homologous recombinants were isolated by positive and negative selections with G418 and ganciclovir (Roche Products, Hertfordshire, UK), and the targeted allele was detected by PCR and confirmed by Southern blotting. Southern blotting was performed using two probes (outer and inner) after KpnI digestion. The wild-type fragment after $K p n \mathrm{I}$ digestion is $1.8 \mathrm{~kb}$ shorter than the targeted allele. The Southern blotting was performed using GeneScreen Plus (DuPont/NEN, Boston, MA) following the protocol provided by the manufacturer. PCR-based screening was conducted using a pair of genespecific primers (GAGCCAGGGTTCACAAAGTA and CACTCCTCTCCAGGTAACAAC) to detect the wild-type allele and a gene-specific primer (TGTCCTTTTCCCTTGTGTCTGGCTGTCCTA) and a neo ${ }^{\mathrm{R}}$ gene-specific primer (TCGTGCTTTACGGTATCGCCGCTCCCGATT) to detect the targeted allele. The positive ES clones were then injected into C57BL/6 blastocysts at the Transgenic Facility of the Johns Hopkins University School of Medicine.

Immunoblotting. For protein analyses of the SynGAP in mice, wholebrain lysate was prepared from mouse pups at postnatal day 4 (P4) and P5, and an equal amount of protein was loaded and separated by SDSPAGE. The gel was transferred to a polyvinylidene difluoride (Millipore, Bedford, MA) membrane, and the membrane was blocked and immunoblotted as described previously (Lau et al., 1996). The anti-GAP antibody of SynGAP was raised against the fusion protein with a hexahistidine tag in rabbit and purified using the antigen coupled to Affi-Gel 10 column (Bio-Rad, Hercules, CA). Antibodies to NMDA receptor subunits NR1 and NR2B, glutamate receptor 1 (GluR1), SAP102, glutamate receptor-interacting protein (GRIP), and GRIP-associated proteins (GRASP) were produced similarly and have been characterized previously (Lau and Huganir, 1995; Dong et al., 1997; Kim et al., 1998; Ye et al., 2000). The anti-PSD-95 antibody was obtained from Upstate Biotechnology (Lake Placid, NY).

Cortical culture, immunocytochemistry, and statistical analysis. Cortical cultures were made from mouse brains at P0 using the procedure described by Goslin and Banker (1991). The forebrain was isolated from a mouse pup and was prepared and plated individually; the tail from each pup was prepared for DNA analysis, and the genotype was analyzed by PCR. After 13-20 d in culture, the neurons were fixed and stained with affinity-purified antibodies as described previously (Liao et al., 1999, 2001). Statistical analysis was performed as described previously (Liao et al., 1999, 2001)

Slice preparation and electrophysiological recordings. Hippocampal slices were prepared from P90-P120 male wild-type and heterozygous SynGAP mice as described previously (Lee et al., 2000). The experimenter was kept unaware of the genotype. To induce LTP, four episodes of theta burst stimulation (TBS) were delivered at $0.1 \mathrm{~Hz}$, using the baseline stimulation intensity. TBS consists of 10 stimulus trains delivered at $5 \mathrm{~Hz}$, with each train consisting of four pulses at $100 \mathrm{~Hz}$. Pairedpulse long-term depression (PP-LTD) was induced by delivering paired pulses at interstimulus intervals of $50 \mathrm{msec}$ at $1 \mathrm{~Hz}$ for $15 \mathrm{~min}(\mathrm{PP}-1 \mathrm{~Hz})$. The pharmacological isolation of NMDA receptor-mediated synaptic responses was done by switching to artificial CSF (ACSF) with $0 \mathrm{~mm}$ $\mathrm{Mg}^{2+}$ and $10 \mu \mathrm{M}$ 2,3-dihydroxy-6-nitro-7-sulfonyl-benzo[f] quinoxaline (NBQX). To confirm the isolation of NMDA receptor responses, 100 $\mu \mathrm{M}$ D,L-APV was perfused at the end of each experiment.

An input-output curve was generated by varying the stimulus intensity. The resulting field potential (FP) slope was then plotted against fiber volley amplitude to control for possible variability in recruiting presynaptic fibers. In the case of pharmacologically isolated NMDA receptormediated responses, FP amplitude was plotted against fiber volley amplitude.

\section{Results}

\section{SynGAP mutant mice die shortly after birth}

To explore the possible role of SynGAP in vivo, the SynGAP gene was disrupted in mice. The genomic DNA containing the $5^{\prime}$ end of the mouse SynGAP gene was isolated and analyzed for targeting vector construction. SynGAP is extensively spliced at the $5^{\prime}$ end, leading to splice variants: SynGAP-a, -b, -c, and -d (Chen et al., 1998; Kim et al., 1998; Li et al., 2001) (Fig. 1A). Therefore, the exon cassette containing the first common methionine present in the shortest splice variant, SynGAP-c, was chosen for deletion, along with an adjacent exon encoding a portion of the $\mathrm{C} 2$ domain by replacing it with a neo ${ }^{\mathrm{R}}$ gene cassette in the reverse orientation (Fig. $1 B$ ). The normal splicing events in the targeted SynGAP gene are predicted to yield transcripts with premature stop codons. The targeted and the wild-type alleles can be differentiated by performing Southern blotting after the KpnI digestion using the inner and outer probes (Fig. $1 B$ ), and the genotyping result can also be confirmed by PCR using the primers shown (Fig. 1C, right).

The chimeric male mice from two independent ES clones (17.28 and 18.8) were mated with C57BL/6 female mice to generate heterozygotes, and sibling mating of heterozygotes produced homozygotes. The $\mathrm{F}_{2}$ mice genotypes exhibited a Mendelian ratio of $1: 2: 1$, indicating that there is no embryonic lethality caused by the null mutation of the SynGAP protein or abnormal segregation of the gene. A database search revealed that the SynGAP gene is on mouse chromosome 17. A sample Southern blotting analysis of the $\mathrm{F}_{2}$ mice is shown in Figure $1 C$, left, where the mobility of the targeted allele differs from that of the wild type after the KpnI digestion because the neo ${ }^{\mathrm{R}}$ gene does not contain the restriction site. The heterozygotes are indistinguishable from the wild types in their size and activity, and they breed normally. The homozygotes are indistinguishable from the wild types and the heterozygotes for the first $2 \mathrm{~d}$ after birth. By the third day the mutant mice begin to show less movement and do not feed from the mother mice. Between P4 and P6, the pups stay small in size, and they die between P5 and P7. These observations were confirmed in the two independent mutant mouse lines.

\section{SynGAP gene targeting abolishes the expression of the wild-type SynGAP protein}

Immunoblot analysis of mouse brain homogenates at P5 with the anti-GAP SynGAP antibody showed that expression of the 130 $\mathrm{kDa}$ SynGAP protein is abolished in the mutant mice (Fig. 2 A). However, overexposure of the immunoblot showed that a very low level of a smear of smaller proteins $(\sim 120 \mathrm{kDa})$ could be detectable using the anti-GAP antibody. These are most likely 

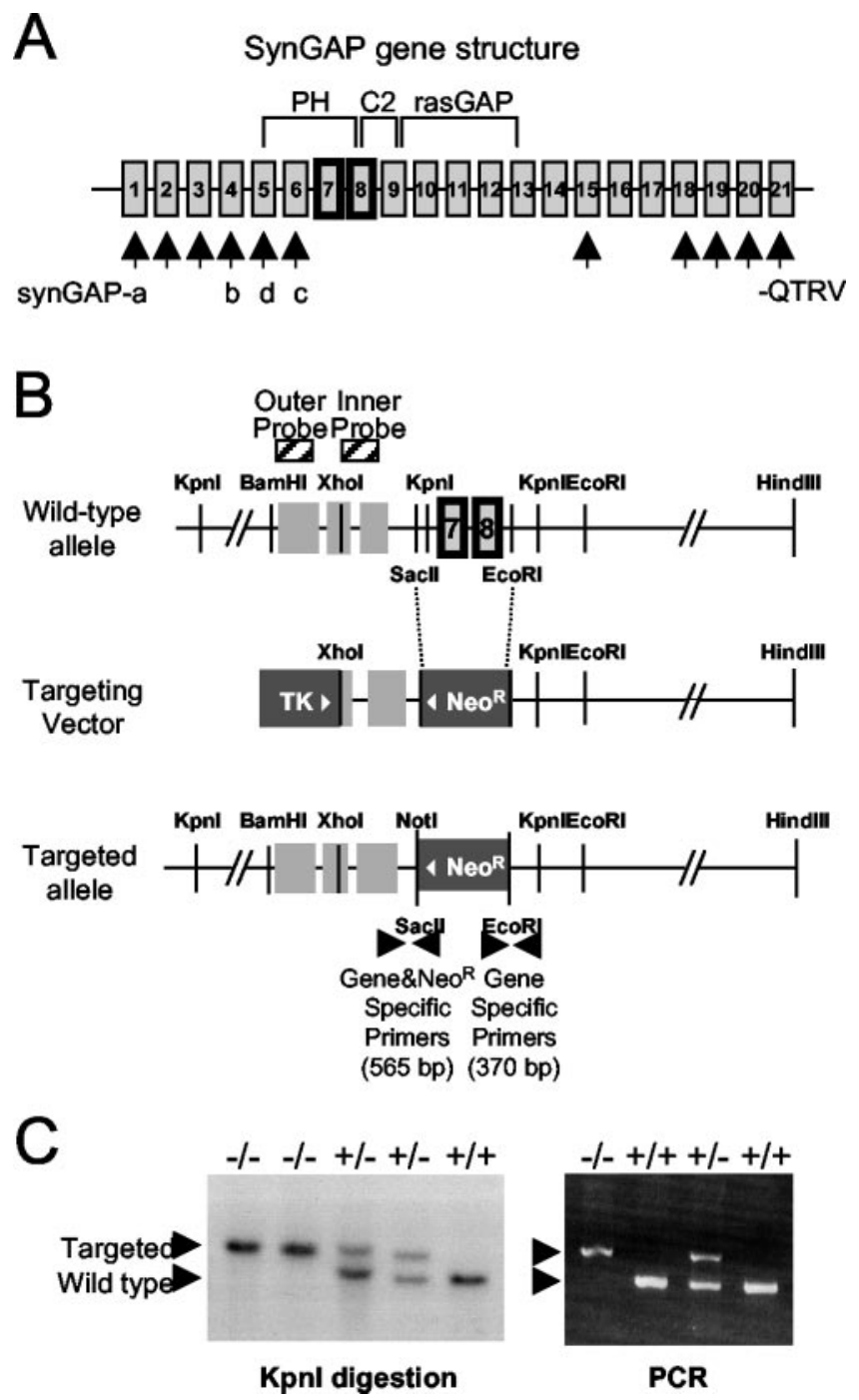

Figure 1. SynGAP splice variants and domain structure and gene targeting strategy. $A$, $\mathrm{N}$-terminal splicing leads to different start sites and sequences in SynGAP-a, $-b,-c$, and $-\mathrm{d}$. SynGAP protein contains a pleckstrin homology $(P H)$ domain, a phospholipid-dependent $\mathrm{Ca}^{2+}$ binding motif (C2) domain, a Ras GTPase-activation protein (RasGAP) domain, and a C-terminal sequence PSD-95/discs large/zona occludens-1 domain binding motif (QTRV). Alternative splicing occurs also at the $C$ terminal with C-terminal sequences other than - QTRV. B, The SynGAP gene structure is shown (not drawn to scale) of the region analyzed for gene targeting. Targeting of the SynGAP gene was performed by replacing the Sacll and EcoRl fragments of the SynGAP gene containing two exons with the ne ${ }^{R}$ cassette. The targeting construct spanning the Xhol and Hindlll fragment of the SynGAP gene is $11.5 \mathrm{~kb}$ long. Outer and inner probes were used for Southern blotting. The PCR primers used for genotyping and the predicted amplified sizes are shown. $T K$, Thymidine kinase. $C$, Genotype analyses of tail DNA of second filial generation $\left(F_{2}\right)$ mice by PCR and Southern blotting. The wild-type allele is detected by Southern blotting after digestion with the $\mathrm{Kpnl}$ restriction enzyme (left). The size of the detected wild-type band is 1.8 $\mathrm{kb}$ longer than that of the targeted allele. Two alleles can be distinguished using PCR primer sets (right).

protein products of the SynGAP gene from cryptic start sites downstream of the deleted exons in the targeted gene. These protein products are present at $<2 \%$ the level of the wild-type SynGAP protein. To analyze whether deletion of SynGAP affected the expression of other neuronal proteins, various synaptic proteins were surveyed in the SynGAP mice at P5 (Fig. 2B). NMDA receptor subunits, NR1 and NR2B, and associated proteins, PSD-95 and SAP102, were similar in expression level in all genotypes. Also, the level of the AMPA receptor subunit GluR1 and the AMPA receptor-associated proteins GRIP1 and GRASP1
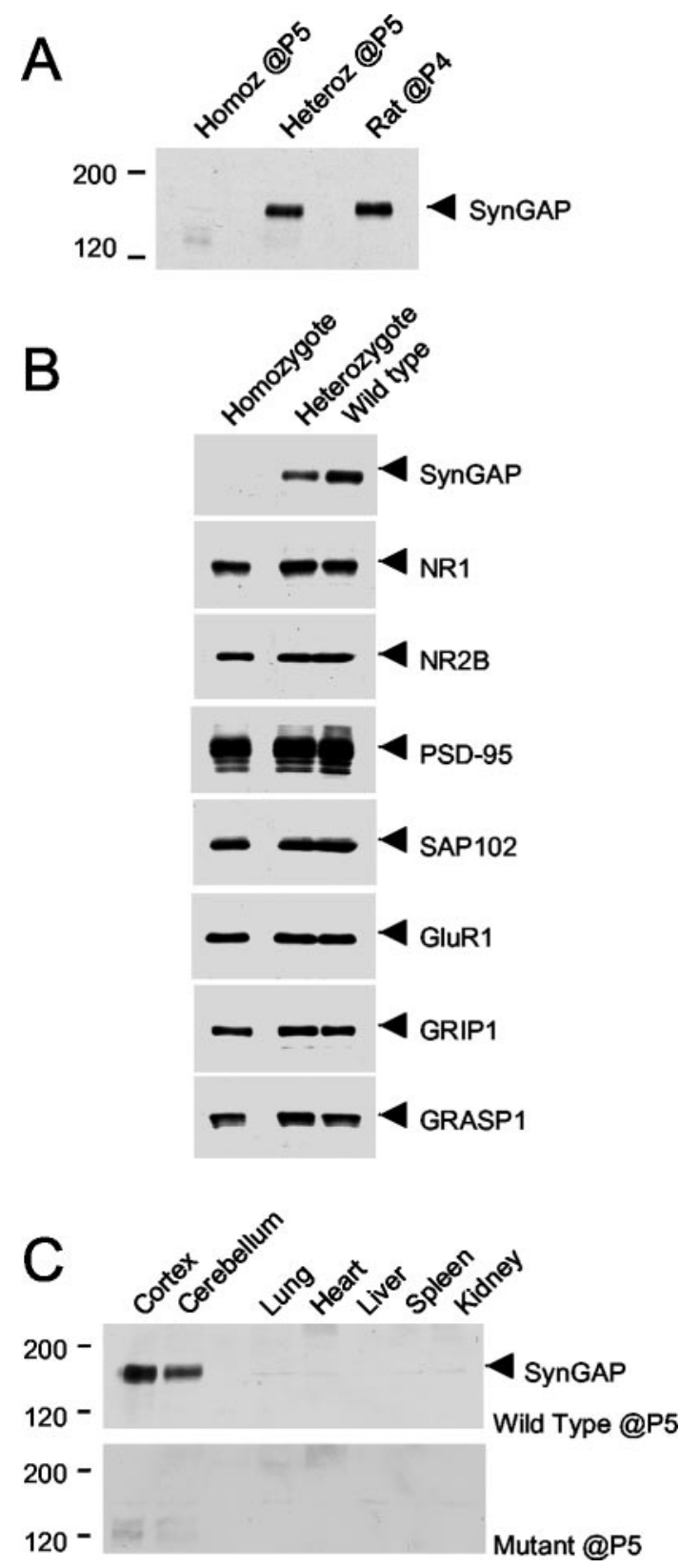

Figure 2. A proper expression of SynGAP protein is abolished in the mutant mice, whereas other synaptic proteins are not affected at $P 5$. $A$, Mouse brain homogenates were prepared and immunoblotted with the anti-GAPSynGAP antibodies at $P 5$ and compared with that of rat brain homogenate at P4. With an equal amount of protein loaded in each lane, SynGAP protein expression is absent in the sample from a homozygous (Homoz) mouse. Heteroz, Heterozygous. $B$, The expression of proteins at synapses was examined in the SynGAP mice using the antibodies to the proteins indicated, and no detectable change in the expression was seen. C, Tissue distribution of SynGAP protein in the mutant and the wild-type mice at $P 5$ was examined using the $\alpha$-GAP domain antibody. In wild-type mice, a prominent band of $\sim 130 \mathrm{kDa}$ was detected in the cortex and the cerebellum. In contrast, the $\sim 130 \mathrm{kDa}$ protein was not detected in the homozygotes or in non-neuronal tissues.

were indistinguishable in the wild types, heterozygotes, and homozygotes.

Brain development in the SynGAP mutant mice

Examination of the SynGAP mutant mice at a gross anatomical level reveals typical development of tissues and organs, similar to the wild-type mice. Because SynGAP protein expression is selectively expressed in the brain (Fig. 2C), it seems likely that the 
prenatal development of non-neuronal tissues is not affected by the absence of SynGAP protein. Brain development at the gross anatomical level also seems normal in the mutant mice. The formation and organization of the forebrain appears to be similar in mice of all three genotypes at P5, as revealed by Nissl staining (data not shown). However, the size of the mutant mouse brain is significantly smaller, indicating that SynGAP may be crucial to the proliferation and development of neuronal tissues after birth, especially around P3. It is not clear why the SynGAP mutant mice die (see Discussion).

\section{Decreased number of silent synapses in neurons cultured from homozygous mice}

To investigate the role of SynGAP during synaptogenesis, cortical neuronal cultures were prepared from SynGAP mice and analyzed after 18-20 d in vitro (DIV). The neurons were fixed, and immunocytochemistry was performed using an anti-synaptophysin antibody to identify synapses, anti-GluR1 and anti-GluR2/3 antibodies to identify AMPA receptors, and anti-NR1 antibody for NMDA receptors. In heterozygote and homozygous neurons, synapses, identified by the anti-synaptophysin antibody, were present in similar numbers [heterozygote mice, $94.1 \pm 4.7$ (SD) of wild-type mice, $p<0.68$; homozygote mice $109.4 \pm 4.9 \%, p<0.49$ of wild-type mice] and

A
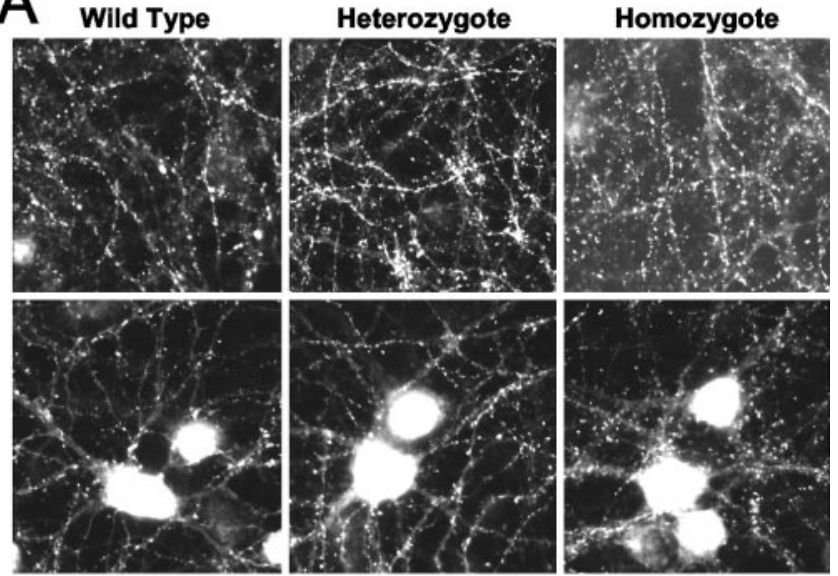

B

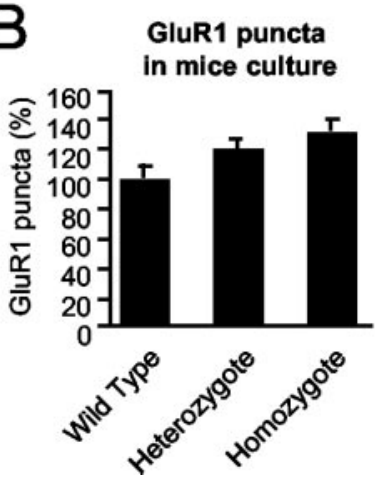

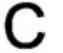

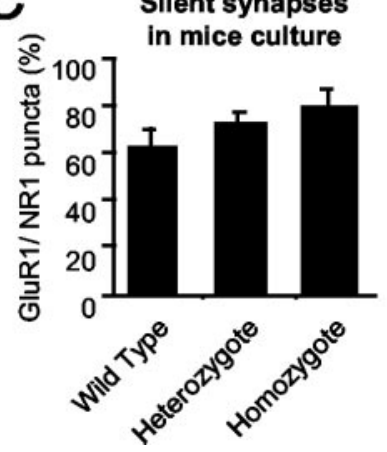

Figure 3. The number of AMPA receptor clusters in the SynGAP mutant mice is increased. $A$ Primary cortical cultures from the SynGAP mutant mice and their wild-type and heterozygous littermates were immunostained with anti-GluR1 antibodies after 18-20 DIV. There was an increase in the number of GluR1-positive clusters in the cultures prepared from the homozygous pups. $B$, Quantitation of GluR1-positive puncta in SynGAP mouse neuronal cultures at 18-20 $\operatorname{DIV}(n=14, n=19$, and $n=13$, respectively; $p<0.05 ;$ ANOVA; $F=3.52)$. C, The number of morphological silent synapses in the cultures was quantitated by comparing the number of AMPA receptor cluster/NMDA receptor cluster puncta ( $n=9, n=13$, and $n=7$, respectively) at $18-20$ DIV. pattern to those in wild-type neurons. Interestingly, AMPA receptor clusters, identified by the anti-GluR1 antibody, were present in a greater number in the homozygotes than in the heterozygotes and the wild-types (Fig. 3A). A similar result was obtained using the anti-GluR2/3 antibody. Quantitation of the number of AMPA receptor puncta is shown in Figure 3B. The number of GluR1-positive clusters was increased in the homozygotes by $32.1 \pm 9.0 \%(p<0.05$; ANOVA) compared with the wild types (Fig. 3 ) and was also higher in the heterozygotes $(21.4 \pm 8.6 \%)$. There was a slight increase in the number of NMDA receptor puncta, although this was not statistically significant ( $p>0.05$; ANOVA; data not shown). Because the number of AMPA receptor clusters increased more than the number of NMDA receptor clusters, we determined whether the number of morphological silent synapses (synapses that contain NMDA receptors but not AMPA receptors) (Liao et al., 1999, 2001) was increased in the mutant mouse. The cultures from the SynGAP mutant mice had significantly fewer morphological silent synapses than their wild-type littermates (Fig. 3C).

\section{Synaptic plasticity in SynGAP knock-out mice}

We tested the role of SynGAP in hippocampal synaptic plasticity by comparing the magnitude of LTP and LTD in the CA1 region of adult wild-type and heterozygous mice. LTP induced by TBS was significantly decreased in slices from heterozygous mice (140 $\pm 6 \%$ of baseline at $1 \mathrm{hr}$ after TBS; $n=20$ slices from five animals) compared with their wild-type littermates ( $174 \pm 9 \%$ of baseline; $n=16$ slices from five animals; $p<0.01$; Student's $t$ test) (Fig. $4 A$ ). Next we tested whether LTD is affected in the SynGAP heterozygotes. To examine LTD, we used paired pulses at an interstimulus interval of $50 \mathrm{msec}$ repeated at $1 \mathrm{~Hz}$ for $15 \mathrm{~min}(\mathrm{PP}-1 \mathrm{~Hz})$, which has been used previously to induce LTD in hippocampal slices from adult rats (Kemp et al., 2000). As shown in Figure $4 B$, there was no difference in the magnitude of LTD in the heterozygous animals $(80 \pm 3 \%$ of baseline measured $1 \mathrm{hr}$ after the start of PP-1 Hz; $n=21$ slices from four animals) compared with wild-type littermates ( $82 \pm 4 \%$ of baseline; $n=18$ slices from four animals; $p>0.4$; Student's $t$ test). In mice, LTD induced by the PP-1 Hz protocol is completely blocked by bath application of the NMDA receptor antagonist APV (data not shown).

The phenotype seen in heterozygotes was not attributable to changes in AMPA receptor-mediated synaptic transmission, because there were no detectable differences in the input-output curve (Fig. 4C). Presynaptic function measured by the pairedpulse facilitation ratio at interstimulus intervals ranging from 25 to $1600 \mathrm{msec}$ were also normal in the heterozygotes (Fig. 4D). To rule out the possibility that the reduced LTP in the SynGAP heterozygotes is attributable to alterations in NMDA receptormediated synaptic responses, we pharmacologically isolated NMDA receptor-mediated components of synaptic transmission by recording in ACSF with $0 \mathrm{~mm} \mathrm{Mg}^{2+}$ and $10 \mu \mathrm{M}$ NBQX. The magnitude of the NMDA receptor-mediated response was measured by generating an input-output curve. We plotted NMDA receptor-mediated FP amplitude against the fiber volley amplitude to correct for variability in recruiting presynaptic fibers. As shown in Figure $4 E$, there is no significant effect on NMDA receptor-mediated responses in the heterozygotes.

\section{Discussion}

SynGAP is a neuron-specific RasGAP that interacts with PSD-95 and SAP102, members of the PSD-95 protein family. The PSD95/SAP90 protein family is composed of proteins with an organized domain structure that forms complexes at synapses with many proteins, including NMDA receptors (Scannevin and $\mathrm{Hu}-$ 
A
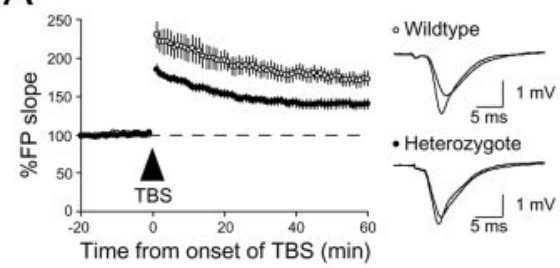

B
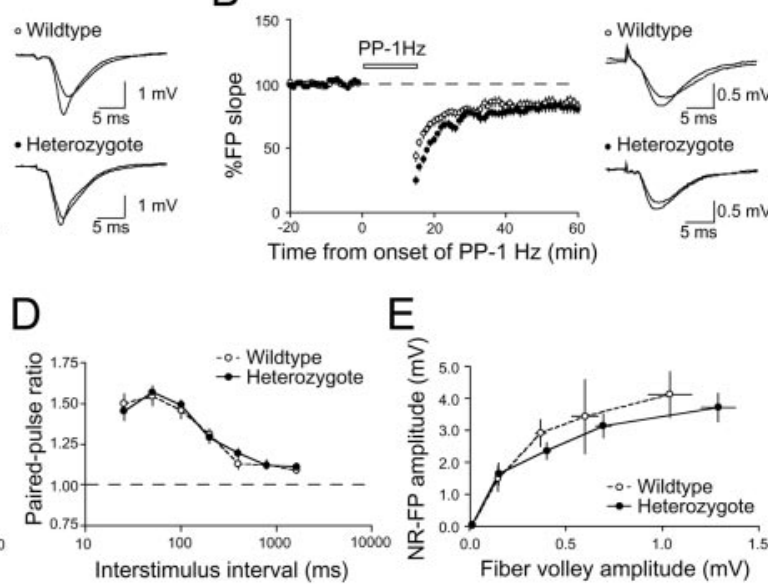

Figure 4. $\quad A$, Schaffer collateral to CA1 LTP in adult SynGAP heterozygotes $(0 ; n=20$ slices from 5 animals) are significantly reduced compared with wild-type littermates $(O ; n=16$ slices from 5 animals). FP traces taken just before and $1 \mathrm{hr}$ after TBS for wild types and heterozygotes are shown to the right. $B$, No significant difference in PP-LTD (PP-1Hz) in SynGAP heterozygotes ( $n=21$ slices from 4 animals) and wild types $(\bigcirc ; n=18$ slices from 4 animals). FP traces taken just before and $1 \mathrm{hr}$ after the initiation of PP-1 Hz are shown to the right. C, AMPA receptor-mediated synaptic transmission measured as the initial FP slope plotted against fiber volley amplitude. Plots of both wild types $(\bigcirc ; n=32$ slices from 8 animals) and heterozygotes $(0 ; n=33$ slices from 8 animals) essentially overlap, suggesting that synaptic transmission is normal in heterozygotes. $D$, No difference was observed in presynaptic function as monitored by paired-pulse facilitation between wild types $(\bigcirc ; n=14$ slices from 5 animals) and heterozygotes ( $; n=14$ slices from 5 animals). Paired pulses were given at interstimulus intervals of $25,50100,200,400$, 800 , and 1600 msec at baseline stimulus intensity. E, Pharmacologically isolated NMDA receptor-mediated synaptic transmission does not differ much between SynGAP heterozygous and wild-type littermates. NMDA receptor-mediated synaptic responses were pharmacologically isolated by bath application of ACSF with $0 \mathrm{~mm} \mathrm{Mg}^{2+}$ and $10 \mu \mathrm{MNBQX}$. An input- output curve was generated by plotting the amplitude of NMDA receptor (NR)-mediated FP against fiber volley amplitude. At the end of each experiment, 100 $\mu \mathrm{M} \mathrm{D,L-APV}$ was added to the bath, completely abolishing the responses (data not shown). Dashed lines indicate normalized FP and paired-pulse facilitation ratio.

ganir, 2000). The family of PSD-95 proteins is thought to serve various functions at the synapse, including providing a scaffold for stabilizing NMDA and AMPA receptors at the synapse and for the recruitment of other synaptic signaling proteins such as neuronal nitric oxide synthase and SynGAP (Scannevin and Huganir, 2000). Mice with mutations in the PSD-95 protein have been shown to have normal synaptic transmission but have a larger LTP compared with wild-type mice (Migaud et al., 1998), suggesting that PSD-95 could modulate synaptic plasticity by regulating downstream signaling complexes. SynGAP is associated with PSD-95 and is in close apposition to NMDA receptors; thus, it is well poised to regulate synaptic transmission and plasticity.

To test this hypothesis, we used conventional gene disruption methods to generate SynGAP null mutant mice. This was confirmed by the altered structure of the SynGAP gene using Southern blotting and PCR analyses and the absence of SynGAP protein expression using SynGAP antibodies. A survey of other synaptic proteins at $\mathrm{P} 5$ revealed no difference in the pattern of expression in the heterozygotes and the homozygotes.

SynGAP mutant mice are born with no gross anatomical abnormality but become sickly by $\mathrm{P} 4$ and die by P7. Gross examination of the brain structure and development showed that the brain formation in the mutant mice is similar to that of the wildtype mice, although the mutant brains were significantly smaller than the wild-type brains. Together, these results suggest that SynGAP is critical for the survival of the animal during early development, but the exact cause of death is not known.

One possibility is that SynGAP is important for NMDA receptor signaling pathways involved in postnatal development. Genetic analyses of NMDA receptor subunits in mice have highlighted the importance of NMDA receptor function for mouse development. In

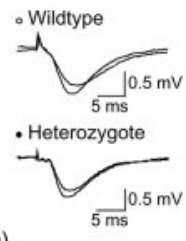

particular, mice with an NR1 null mutation, which leads to an absence of functional NMDA receptors, die perinatally with no obvious morphological abnormalities in the brain (Forrest et al., 1994; Li et al., 1994). Also, a null mutation in NR2B leads to death shortly after birth (Kutsuwada et al., 1996). A specific deletion of the intracellular domain of NR2B also leads to perinatal death, indicating that the intracellular domain is required for proper function of the receptors, which is critical for survival in neonates (Sprengel et al., 1998). The similarity in phenotypes between the NMDA receptor and SynGAP mutants suggests that SynGAP present in the NMDA receptor complex at excitatory synapses may mediate NMDA receptor-dependent signal transduction pathways important for proper neuronal development.

Because the mutant animals die perinatally, before the glutamatergic synapses are forming, we prepared dissociated cortical neuronal cultures to assess whether synapses are affected in the absence of SynGAP protein expression. Using various antibodies to mark glutamatergic synapses, we observed that the formation and organization of synapses in the mutant neuronal cultures are different. AMPA receptors and NMDA receptors were seen in clusters and colocalized with synaptophysin staining in mutant cultures, but the number of AMPA receptor clusters was increased compared with the wild-type littermates. How does the null mutation of SynGAP affect glutamatergic synapse organization? In mutant mice, without proper regulation of Ras by SynGAP, activated Ras at synapses may lead to increased Ras signaling, including activation of the MAPK cascade. Interestingly, a recent study has shown that NMDA receptor-regulated RAS activation affects the synaptic trafficking of AMPA receptors (Zhu et al., 2002). Also, PSD-95 has been shown to accelerate the maturation of excitatory synapses, corroborating the potential role of PSD-95 and SynGAP in their functional contribution to synaptic receptor organization (El-Husseini et al., 2000). We have tried to look at the regulation of Ras and MAPK activity in cultured neurons and in brain homogenates from the mutant mice, but see no consistent changes in the Ras-MAPK signaling. This may be attributable to the fact that SynGAP is exclusively found at excitatory synapses and may not affect the total cellular Ras and MAPK activity. In future experiments we plan to try to selectively measure synaptic Ras and MAPK activity in the mutant animals.

Electrophysiological analyses of the heterozygous SynGAP mutant mice show that LTP is dramatically decreased compared with the wild-type littermates. In contrast, basal transmission, LTD, and AMPA and NMDA receptor function appear normal in heterozygote hippocampal slices. The lack of a detectable increase in AMPA receptor function in the heterozygote hippocampal slices is unexpected, because increases in GluR1 puncta were observed in cultures from the mutant mice. However, this may be attributable to differences in the developmental stage of synapses in culture and in the slice. Future studies will clarify this issue and 
will focus on the role of SynGAP in the regulation of synaptic plasticity at the developing and mature synapse.

In conclusion, these results illustrate a functional contribution of SynGAP in the regulation of synaptic plasticity. The MAPK cascade is a major signaling pathway activated by Ras and also has been demonstrated to be important in LTP. Recent studies have shown that AMPA receptor trafficking may play important roles in LTP (Scannevin and Huganir, 2000), and it is likely that the regulation of SynGAP activity through its effects on Ras and the MAPK pathway may regulate AMPA receptor delivery to synapses during LTP.

\section{References}

Bliss TV, Collingridge GL (1993) A synaptic model of memory: long-term potentiation in the hippocampus. Nature 361:31-39.

Bokoch GM, Der CJ (1993) Emerging concepts in the Ras superfamily of GTP-binding proteins. FASEB J 7:750-759.

Brambilla R, Gnesutta N, Minichiello L, White G, Roylance AJ, Herron CE, Ramsey M, Wolfer DP, Cestari V, Rossi-Arnaud C, Grant SG, Chapman PF, Lipp HP, Sturani E, Klein R (1997) A role for the Ras signalling pathway in synaptic transmission and long-term memory. Nature 390:281-286.

Chen HJ, Rojas-Soto M, Oguni A, Kennedy MB (1998) A synaptic RasGTPase activating protein (p135 SynGAP) inhibited by CaM kinase II. Neuron 20:895-904.

Dong H, O’Brien RJ, Fung ET, Lanahan AA, Worley PF, Huganir RL (1997) GRIP: a synaptic PDZ domain-containing protein that interacts with AMPA receptors. Nature 386:279-284.

El-Husseini AE, Schnell E, Chetkovich DM, Nicoll RA, Bredt DS (2000) PSD-95 involvement in maturation of excitatory synapses. Science 290:1364-1368.

Finkbeiner S, Greenberg ME (1996) $\mathrm{Ca}^{2+}$-dependent routes to Ras: mechanisms for neuronal survival, differentiation, and plasticity? Neuron $16: 233-236$

Forrest D, Yuzaki M, Soares HD, Ng L, Luk DC, Sheng M, Stewart CL, Morgan JI, Connor JA, Curran T (1994) Targeted disruption of NMDA receptor 1 gene abolishes NMDA response and results in neonatal death. Neuron 13:325-338.

Fukunaga K, Miyamoto E (1998) Role of MAP kinase in neurons. Mol Neurobiol 16:79-95.

Garner CC, Kindler S, Gundelfinger ED (2000) Molecular determinants of presynaptic active zones. Curr Opin Neurobiol 10:321-327.

Goslin K, Banker G (1991) Culturing nerve cells. Cambridge, MA: MIT.

Hollmann M, Heinemann S (1994) Cloned glutamate receptors. Annu Rev Neurosci 17:31-108.

Impey S, Obrietan K, Storm DR (1999) Making new connections: role of ERK/MAP kinase signaling in neuronal plasticity. Neuron 23:11-14.

Kemp N, McQueen J, Faulkes S, Bashir ZI (2000) Different forms of LTD in the CA1 region of the hippocampus: role of age and stimulus protocol. Eur J Neurosci 12:360-366.

Kim JH, Liao D, Lau LF, Huganir RL (1998) SynGAP: a synaptic RasGAP that associates with the PSD-95/SAP90 protein family. Neuron 20:683-691.

Kornhauser JM, Greenberg ME (1997) A kinase to remember: dual roles for MAP kinase in long-term memory. Neuron 18:839-842.

Kutsuwada T, Sakimura K, Manabe T, Takayama C, Katakura N, Kushiya E, Natsume R, Watanabe M, Inoue Y, Yagi T, Aizawa S, Arakawa M, Takahashi T, Nakamura Y, Mori H, Mishina M (1996) Impairment of suckling response, trigeminal neuronal pattern formation, and hippocampal LTD in NMDA receptor $\epsilon 2$ subunit mutant mice. Neuron 16:333-344.

Lau LF, Huganir RL (1995) Differential tyrosine phosphorylation of $N$-methyl-D-aspartate receptor subunits. J Biol Chem 270:20036-20041.

Lau LF, Mammen A, Ehlers MD, Kindler S, Chung WJ, Garner CC, Huganir RL (1996) Interaction of the $N$-methyl-D-aspartate receptor complex with a novel synapse-associated protein, SAP102. J Biol Chem 271:21622-21628.

Lee HK, Barbarosie M, Kameyama K, Bear MF, Huganir RL (2000) Regulation of distinct AMPA receptor phosphorylation sites during bidirectional synaptic plasticity. Nature 405:955-959.

Li W, Okano A, Tian QB, Nakayama K, Furihata T, Nawa H, Suzuki T (2001) Characterization of a novel synGAP isoform, synGAP- $\beta$. J Biol Chem 276:21417-21424.

Li Y, Erzurumlu RS, Chen C, Jhaveri S, Tonegawa S (1994) Whisker-related neuronal patterns fail to develop in the trigeminal brainstem nuclei of NMDAR1 knockout mice. Cell 76:427-437.

Liao D, Zhang X, O’Brien R, Ehlers MD, Huganir RL (1999) Regulation of morphological postsynaptic silent synapses in developing hippocampal neurons. Nat Neurosci 2:37-43.

Liao D, Scannevin R, Huganir RL (2001) Activation of silent synapses by rapid activity-dependent synaptic insertion of AMPA receptors. J Neurosci 21:6008-6017.

Marshall CJ (1996) Ras effectors. Curr Opin Cell Biol 8:197-204.

Migaud M, Charlesworth P, Dempster M, Webster LC, Watabe AM, Makhinson M, He Y, Ramsay MF, Morris RG, Morrison JH, O’Dell TJ, Grant SG (1998) Enhanced long-term potentiation and impaired learning in mice with mutant postsynaptic density-95 protein. Nature 396:433-439.

Nicoll RA, Malenka RC (1995) Contrasting properties of two forms of longterm potentiation in the hippocampus. Nature 377:115-118.

Scannevin RH, Huganir RL (2000) Postsynaptic organization and regulation of excitatory synapses. Nat Neurosci 1:133-141.

Sprengel R, Suchanek B, Amico C, Brusa R, Burnashev N, Rozov A, Hvalby O, Jensen V, Paulsen O, Andersen P, Kim JJ, Thompson RF, Sun W, Webster LC, Grant SG, Eilers J, Konnerth A, Li J, McNamara JO, Seeburg PH (1998) Importance of the intracellular domain of NR2 subunits for NMDA receptor function in vivo. Cell 92:279-289.

Sweatt JD (2001) The neuronal MAP kinase cascade: a biochemical signal integration system subserving synaptic plasticity and memory. J Neurochem 76:1-10.

Ye B, Liao D, Zhang X, Zhang P, Dong H, Huganir RL (2000) GRASP-1: a neuronal RasGEF associated with the AMPA receptor/GRIP complex. Neuron 26:603-617.

Zhu JJ, Qin Y, Zhao M, Van Aelst L, Malinow R (2002) Ras and Rap control AMPA receptor trafficking during synaptic plasticity. Cell 110:443-455. 